\title{
The ischemic model of chronic muscle spasm and pain
}

\author{
Roger H. Coletti \\ Interventional Health, PA, Lewes, DE, USA. \\ This article is distributed under the terms of the Creative Commons Attribution Commercial License (CC BY 4.0), which permits any \\ commercial use, distribution, and reproduction in any medium, provided the original author(s) and source are credited.
}

\begin{abstract}
This article was not intended to be a complete review of the electromyography of pathological muscle states, but it was written to illustrate how the "Coletti Method of EMG ChemoDenervation” $\left(\mathrm{CMECD}^{\circledR}\right)$ protocol for the treatment of chronic pain resulting from chronic muscle spasm was developed and established. That process led to an unexpected understanding of the underlying pathophysiology of chronic muscle spasm, which represents a paradigm shift in our understanding and ultimately in our treatment of muscle spasm-induced chronic pain. Other investigators had brought to light the presence of spontaneous electrical activity (SEA) in states of muscle spasm. Those findings were all but ignored by standard EMG/Nerve conduction studies in clinical practice. Starting with a simple EMG device I experimented with various medications to treat patients with chronic pain associated with chronic muscle spasm. Suppression of SEA with long-acting medications resolved both the chronic spasmand chronic pain. A successful protocolusing phenoxybenzamine was established and clinical outcomes were followed. More than 200 patients were successfully treated during last 12 years. Correlating known exercise muscle physiology with the development of the pathological state of chronic muscle spasm as seen by electromyography led to the postulation of the ischemic model of chronic muscle spasm. Light microscopy pathophysiologic supportive findings are presented and discussed. Predictions from this model to various aspects of treatment were supportive. Implications regarding treatment by the $\mathrm{CMECD}^{\circledR}$ procedure, as well as other standard therapies, are discussed. Application of the ischemic model to other pain conditions was explored with implications of therapeutic modification. Recommendations for changes in rehabilitation therapy are discussed.
\end{abstract}

Key Words: Electromyography (EMG); muscle; spontaneous electrical activity (SEA); spasm; pain; phenoxybenzamine - lidocaine - dexamethasone mixture; CMECD ${ }^{\circledR}$ protocol.

Eur J Transl Myol 32 (1): 10323, 2022 doi: 10.4081/ejtm.2022.10323

This article was not intended to be a complete review of the electromyography of pathological muscle states, nor to present the findings of a clinical trial, but it was written to present new concepts and models of skeletal muscle pathophysiology that were realized in the development of the $\mathrm{CMECD}^{\circledR}$ protocol for the treatment of chronic pain resulting from chronic muscle spasm. $\mathrm{CMECD}^{\circledR}$ is an acronym taken from "Coletti Method of EMG ChemoDenervation”. I apologize for the intermingling of a presentation of research findings and concept development with the personal process that was responsible for their acquisition. Any other method of presentation would fail to reveal the essence of scientific investigation when undertaken by a single individual. That process led to an unexpected understanding of the underlying pathophysiology of chronic muscle spasm, which may represents a paradigm shift in our understanding and ultimately in our treatment of muscle spasminduced chronic pain.

\section{Skeletal and Cardiac Muscle Similarities}

Skeletal and cardiac muscle both depend on adequate blood supply. Given the urgency of blood supply to the heart, we know much more about cardiac ischemia than skeletal muscle ischemia. As an interventional cardiologist studying skeletal muscle, the potential role of ischemia in chronic muscle spasmwas an easy concept to grasp. My study of chronic muscle spasm began elsewhere, simply looking for the cause of chronic muscle spasm as central neurogenic, spinal or caused by the muscle itself. Exploring chronic muscle spasms with an electromyography (EMG) made it clear that spontaneous electrical activity (SEA) was always present. Later it became evident that the SEA was what kept the muscle in chronic spasm. Similar to atrial fibrillation, chronic electrical activity and a state of chronic contraction went hand in hand. While we don't recognize fibrillations in muscles in chronic spasm, the 
state of chronic contraction, a sort of skeletal myofibrillation is the skeletal muscle equivalent.

The most basic fact about skeletal and cardiac muscle is that it takes energy to relax, as well as to contract. ${ }^{1}$

There is a literature regarding the energy crisis of muscle spasm. The role of muscle spasm causing local muscle ischemia has now been reported by several authors. ${ }^{2,3}$ Unfortunately, it does not correlate that hypothesis with the generation of SEA that continues to be considered only "end plate noise". ${ }^{4}$

It is known from cardiac tissue that ischemic myocardium has a high arrhythmic potential. Ventricular and atrial fibrillation, ventricular and atrial tachyarrhythmias flourish in ischemic tissue. ${ }^{5}$ SEA appears to be no different and the result of ischemia. Inadequate energy molecules to support the sodium, potassium and calcium channels lead to membrane instability. The state of severe membrane instability is SEA and mild membrane instability results in increased insertional activity. Thus, the energy crisis is the prime mover and not the result of chronic muscle spasm. Ischemic cardiac muscle also demonstrates what is called diastolic dysfunction and can cause heart failure even if the overall cardiac contraction falls within normal range. It is called heart failure with preserved ejection fraction. ${ }^{6}$ Cardiac muscle can become ischemic with narrowed coronary arteries but also with persistent tachycardia. It results in tachycardia induced cardiomyopathy. ${ }^{7}$ The heart receives its predominant coronary blood flow in diastole as systole limits capillary flow. Unpublished basic research by this author found that reducing the strength of cardiac contraction would at a certain level reverse the systolic vs. diastolic flow ratio. Prolonged tachycardia provided less relative time for coronary blood flow resulting in relative ischemia. The cardiomyopathy that results typically normalizes with slowing of the heart rate but takes months to recover. Light microscopy structural changes occurred from the is chemia. Simple coronary ischemia can also give rise to hibernating myocardium with similar findings and reversibility. ${ }^{8}$

Work by Ugo Carraro found similar changes in skeletal muscle that had been in a state of chronic spasm ${ }^{9}$ Chronic spasm of skeletal muscle, in a similar way as found in cardiac muscle, induces a state of chronic ischemia. He showed reversibility of the light microscopy structural changes with therapy of the chronic spasm. ${ }^{10}$ Although it was not identified as such at that time, he discovered and characterized "hibernating skeletal muscle”. His work has provided the strongest support for the presence, effect, and recovery of ischemic muscle tissue in chronic muscle spasm.

Getting to the realization that ischemia was the central principle did not come right away. Moreover, my initial focus was on chronic pain and its association with chronic muscle spasm. Ultimately, I had 12 abstracts accepted for publication in Muscle \& Nerve and I defended the poster presentations at sixnational meetings
Table 1. Abstracts published in Muscle \& Nerve

The twelve abstracts published in Muscle \& Nerve were as follows:

- EMG Guided Chemodenervation Treatment of Sciatica - accepted 2012

- Novel Injection Technique for Chemodenervation of Symptomatic Chronic Muscle Spasm - accepted 2014

- Needle Electromyographic Identification of Chronic Muscle Spasm - accepted 2016

- Debunking the Myth: Denervated Muscle is the Solitary Cause of Muscle Spontaneous Electrical Activity - accepted 2017

- Successful Treatment of Longstanding Chronic Muscle Spasm with EMG Guided Chemodenervation - accepted 2017

- Safety of Phenoxybenzamine Chemodenervation with Repeated Injections- accepted 2017

- Proposed New Diagnostic Entity of Acquired Chronic Muscle Spasm - accepted 2018

- EMG Guided Chemodenervation Procedure of Acquired Chronic Muscle Spasm Designated as CMECD $^{\circledR}$ - accepted 2018

- Limitations of EMG and Nerve Conduction Studies in Clinical Practice - accepted 2018

- Non-Skeletal Etiology of Foot Drop with Therapeutic Reversal - accepted 2019

- Staged Healing of Wrist Tendonitis Following CMECD $^{\circledR}$ Treatment - accepted 2019

- Pattern of Recovery of Acquired Chronic Muscle Spasm Consistent with Ischemic Injury Model - accepted 2019.

of the American Association of Neuromuscular and Electrodiagnostic Medicine (Table 1).

By 2012 I had identified the presence of SEA in chronic muscle and developed methods to use Botox ${ }^{\circledR}$ (Onabotulinumtoxin A) and later phenoxybenzamine to treat chronic spasm and relieve sciatica.

\section{EMG Hyperactivity}

Janet G. Travel had first described and characterized myofascial trigger points. ${ }^{11}$ David G. Simons had identified what was described as endplate noise and spikes at the site of myofascial trigger points. ${ }^{11}$

David R. Hubbard, Jr had done trials injecting myofascial trigger points that demonstrated EMG hyperactivity with several medications including phentolamine, curare and phenoxybenzamine and monitored the response of a two channel EMG signal. ${ }^{12}$ He performed several clinical 
trials with phenoxybenzamine for chronic spasmbut did not come up with a successfulprotocol. ${ }^{13}$

I did not seek to identify trigger points. I had patients with chronic pain and clear evidence of muscular spasm that by history was chronic. EMG findings of marked spontaneous electrical activity (SEA) were readily appreciated. Rather than trying to inject a trigger point, I chose to use small doses diffusely with a much weaker concentration of phenoxybenzamine throughout the muscle wherever there was SEA. SEA was completely abolished with this technique. I had already learned that phenoxybenzamine injected by itself was painful, having tried it on myself and knew from the literature that its effects could take up to an hour to work. Fortuitously, Lidocaine had a similar $\mathrm{pH}$ of 3 to phenoxybenzamine and could be mixed. Furthermore, Lidocaine immediately suppressed the SEA allowing me to assess if all the tissue exhibiting SEA was adequately treated. Sixty to ninety minutes later as the Lidocaine effect wore off, the effect of the phenoxybenzamine could be demonstrated. Nonetheless, phenoxybenzamine is a tissue irritant and a small dose of dexamethasone was added to minimize the early inflammatory effects. The final concentration of phenoxybenzamine was one fifth to one tenth of what Dr. Hubbard had used in his clinical trials. ${ }^{13}$ With the use of this cocktail of medications, the use of phenoxybenzamine became the preferred medication, as Botox $^{\circledR}$ was expensive, not being reimbursed for my treatments and ultimately abandoned because of its tendency to cause atrophy and weakness. ${ }^{14}$

\section{Videos as a Teaching Tool}

I have posted a few relatively amateurish videos online to demons trate both the appearance of SEA, its res olution with the $\mathrm{CMECD}^{\circledR}$ procedure and examples of two sites where it is applicable. The URL's for each are found in the Video References. The first is treatment of IT Band Syndrome with injection of the tensor fasciae latae muscle: V1. ${ }^{15}$ The second is just an example of cessation of SEA with the injection: V2. ${ }^{16}$ The third is treatment of chronic back muscle spasm with $\mathrm{CMECD}^{\circledR}$ procedure: V3. ${ }^{17}$

Very recently, concentrations of as little of one tenth of what I had used for the past 12 years were tried and seem to be effective with less irritant effect. Outcome data, however, are not yet available and considerable clinical evidence will be necessary before changing the current protocol.

\section{Safety and Outcome Data}

Having demonstrated how to identify the muscles in chronic spasm, having developed a simple protocol for use of phenoxybenzamine and having demonstrated the effectiveness of phenoxybenzamine in certain cases of chronic pain, the next was assessing the issue of safety of the drug compared to Botox ${ }^{\circledR}$. There was evidence that repeated use of Botox ${ }^{\circledR}$ could result in weakness and atrophy of muscle. ${ }^{14}$ As it happened, I personally had a very bad case of post-laminectomy syndrome with recurrent back muscle spasms. As with many scientists, self-administration of the potential cure was necessary. A dozen or so of self-injection into my back muscles demonstrated no evidence of weakness. I was even able at one point to demonstrate by MRI's that a wayward disc went back into place with relief of a paraspinal muscle spasm.

Ultimately, having treated about two hundred patients, it became necessary to collect data on the results. As more than 30 different muscle groups had been treated, I chose not to use a double-blind study but self-ass es sment by the patients. Not only was the degree of relief or lack of relief charted but also the length of time the patient had suffered with the spasm and pain was charted. The data I then presented included multiple occasions where the chronic pain from chronic muscle spasm had been present for one to five years. One individual cited pain for 15 years and another for over 30 years that resolved entirely with one or two injections.

What I have failed to mention up to this point is that typically only a single injection is needed. If areas of muscle still in spasm had been missed, then a second injection to complete the area to be treated was all that was needed. Phenoxybenzamine is known to form a covalent bond with the adrenergic receptor and the net duration of effect of the injection is two to three months while the muscle must grow new receptors. This two-tothree-month suspension of spasm gives the muscle time to recover from the chronic ischemic changes. Recovering muscle that was cut in a laminectomy procedure, as was the case for my surgery, will grow new receptors at a much quicker rate and lessen the duration of action of phenoxybenzamine to about two weeks.

I surveyed the most recent 100 patients that I had treated. About one third of the 100 patients surveyed responded. Of the respondents, 31 (74\%) reported years of pain duration. Of those, $50 \%$ reported complete relief of pain (81\% of which reported relief of pain for greater than 3 months) and $27.4 \%$ reported moderate relief of pain (44\% of which reported pain relief for greater than 3 months). The average duration of pain when specified was 5 years and the longest was 15 years. Pain relief of greater than 3 months was taken as success for long term relief of pain as the phenoxybenzamine effect had worn off by that time. More details are reported in Table 2 and Table 3.

A single treated patient, not listed in the tables, reported near complete pain relief and return of function after 35 years.

\section{New Models and Concepts}

My clinical and EMG findings were at odds with beliefs held by neurologists, physical medicine specialists and the textbooks. My abstract was accepted that challenged the fixed notion that spontaneous electrical activity in skeletal muscle is only present in denervated muscle. ${ }^{18}$ To facilitate conversation with the neurology world, I 
Table 2. Questionnaire on Response to Treatment with $C M E C D^{\circledR}$ procedure

Mailing with Negative Results

Two mailings were made to the most recently treated 92 patients.

Returns of the first mailing of 50 assessment forms: 21 ,

Returns of the second mailing of 70 forms: 21,

Total returns: 42

Number stating no pain relief in first mailing: 2, in second mailing: 5

(second mailing specifically requested patients without relief to respond)

Number / percent of patients with no pain relief: 7 / $16.6 \%$

Number of patients with no pain relief that had subsequent procedures: 3

Number of patients who had subsequent back surgery: 2

\section{Mailing with Positive Results}

Number / Percent with significant relief of pain: 35 / 83.3\%,

Complete relief of pain: $22 / 50 \%$,

Moderate pain relief: 9 / 21.4\%

Partial pain relief: 4 / 9.5\%.

Number / Percent of patients who had prior unsuccessfultreatments: 34 / 85\%

Number / Percent of patients with prior back surgery: 5 / 12\%

Number / Percent of prior back surgery patients with complete durable relief: 2 / 5\%

designated "acquired chronic muscle spasm” as a new diagnostic entity, ${ }^{19}$ as opposed to neurogenic chronic muscle spasm, i.e., spasticity, as seen in post stroke patients and other neurogenic conditions. The conditions that were required to meet that designation were specified. The neurology texts did not recognize “acquired chronic muscle spasm” or anything remotely similar, not even muscle spasmwas to be found.

I had knowingly placed my findings and the information of the technique in the public domain previously so that it could not be patented by me or by anyone else. This was to make sure that its use could not be limited. To give some permanence to the technique, I designated the procedure as $\mathrm{CMECD}^{\circledR}$ (Coletti Method of Emg ChemoDenervation) and trademarked it. ${ }^{20}$
Table 3. Questionnaire on Response to Treatment with $C M E C D^{\circledR}$ procedure

Impact on overall health, wellbeing or ability to function (number $/ \%$ )

No response to question: 2 / 4.8\%,

No impact: 11 / 26\%,

Minor impact: 6 / 14\%,

Major impact: 23 / 55\%,

Minor or major impact: 29 / 69\%.

Decrease in use of pain medications (number /\%)

No response: 5 / 12\%

Took no pain meds before: 9 / 21.4\%

No change in use of pain meds because of no pain relief: 9 / 21.4\%

Mild decrease in use of pain meds: 4 / 9.5\%

Moderate decrease in use of pain meds: 5 / 12\%

No longer needed pain meds: 18 / 42\%,

Decrease in use or no longer needed pain meds: 27 / 64.3\%.

The website CMECD.info is a physician teaching site that not only provides the abstracts but also much additional information in the background, support, and utilization of the procedure.

It became apparent that current EMG/Nerve conduction studies were inadequate as they did not consider chronic muscle spasm. An abstract was accepted that detailed the limitations of current EMG/Nerve conduction studies. ${ }^{21}$ These studies do not take into account chronic muscle spasm as a cause of chronic pain and weakness. It was clear that muscles in chronic spasm, especially when causing chronic pain, needed to be identified as a cause of weakness. It was also apparent that muscles in chronic spasm were not candidates for strengthening when attempting physical therapy. It was proposed to report the presence, location, and severity of SEA as a part of EMG/Nerve conduction studies.

Another chronically held belief was that nerve compression was always caused by skeletal involvement. Clinical examples of non-skeletal foot drop and piriformis syndrome with reversal of symptoms were presented in an abstract that demonstrated the inaccuracy of that belief. ${ }^{22}$

Getting back to the work of Ugo Carraro and the light microscopy structural changes found in muscles in chronic spasm, I presented evidence of a pattern of muscle recovery that supported ischemia as the underlying cause of chronic muscle spasm. I had since 
put forth a model of chronic muscle spasm that I have named the "Black Hole Model of Chronic Muscle Spasm”. This is a conceptual model to highlight the fact that once the muscle in chronic spasmhas all but shut off its blood supply, it is left in a black hole. Recovery cannot be spontaneous but requires an outside force to rescue the muscle from the locked in state of the black hole.

My best understanding of what is happening when SEA is present in a portion or all of a given muscle is that: i) muscle membranes are unstable and spontaneously depolarize, ii) these depolarizations act as if there was an external neural stimulus for the muscle to contract, iii) the muscle retains at least a small potential to contract and, in doing so, iv) places more demands on the available energy molecules in an attempt to relax furthering the energy crisis that maintains the membrane instability.

This is most likely a simplistic explanation and a more precise and detailed sequencing of the events needs investigation

\section{Clinical Implications}

The implications of Professor Carraro's work are profound. Muscle in a state of chronic spasm is injured. It has lost mitochondria and the muscle fibers themselves are diminished in size and function.9,10 The energy molecules that will be generated by restoration of blood flow can be readily depleted again by asking the muscle to perform at preinjury levels. Any intervention that stops the SEA can facilitate recovery, but reversal of the injured state by whatever means is a time dependent process.

Functional Electrical Stimulation (FES) was shown by Professor Ugo Carraro to reverse the light microscopy structural damage which I believe was most likely acting as a vascular pump to provide increased blood supply to the chronically ischemic muscle tissue. ${ }^{9}$ This process will quiet the SEA as the membranes stabilize with blood and replenishment of energy molecules. This is a time dependent process.

The use of the $\mathrm{CMECD}^{\circledR}$ procedure will short circuit the SEA activity and allow the muscle to rest by allowing the blood supply to return passively. It is a reproducible clinical finding that when a muscle as treated with the $\mathrm{CMECD}^{\circledR}$ procedure, the muscle that previously could be palpated as firm and tender, was nearly instantly soft and compressible.

The exact mechanism responsible for this transformation remains unclear to me and may warrant investigation. However, it must be kept in mind that although the pain caused by the chronic spasm will stop almost immediately, the muscle remains injured.

All efforts to rehabilitate the muscle must take into consideration the state of the injured muscle. Classic strengthening techniques may well throw the muscle back into that black hole and prevent recovery. Methods must be developed to ass ess the functional capacity of the injured muscle and not ask of it more than the current energy stores can supply. Exercises that exhaust the muscle's capacity to function must be understood as an impediment to eventual recovery. Paradoxically, it is the lack of energy for the muscle to relax that puts it out of commission to contract. This reversal of currently held practices will be among the most difficult to correct.

The predictions of these findings have been borne out, as well as can be anticipated in a loosely supervised clinical trial. There are clear recommendations for patients not to jump to a "flight to health" but with any clinical setting those recommendations are at least occasionally ignored. Subsequent failure of long-term success to resolve chronic muscle spasmand resultant chronic pain in some patients has likely been, at least in part, the lack of compliance with these recommendations.

However, the documentation of long-term success of resolution of chronic pain and spasm in a significant number of treated patients (Table 2 and 3) supports the utility of the $\mathrm{CMECD}^{\circledR}$ procedure.

\section{Opioid Crisis}

At the time that I first sought the answer to the cause of chronic muscle spasm, the opioid cris is had not yet gotten underway. ${ }^{23}$

However, the potential role of the $\mathrm{CMECD}^{\circledR}$ procedure in current times should not be overlooked. None of the hundreds of patients that I treated for chronic pain and chronic muscle spasm were given any type of pain medication and I never wrote a single opioid pain prescription during any of that 15 -year period.

An alternative URL to arrive at the CMECD.info website is opioidNO.com that was chosen to highlight the importance of physician training to treat chronic pain without opioids.

The ability to identify chronic muscle spasm, both clinically and by EMG criteria is essential in choosing a non-opioid treatment for chronic pain. While there is not current data on the percentage of patients with chronic pain secondary to chronic muscle spasm as opposed to other causes, my personal experience is that easily 50\% have associated chronic muscle spasm.

Handheld EMG devices are available at relatively low cost for identification of chronic muscle spasm. With that information in hand, a variety of therapies that can improve the blood flow to the spasmic muscle could be undertaken. Hopefully, such an approach will be able to at least dampen the severity of the current opioid crisis.

\section{Ischemic Model of Tendonitis}

Another interesting direction came in investigating the pathophysiology of tendonitis. It had always been my belief that injuries such as tennis elbow were the result of chronic muscle spasmwith a constant pull on the tendon causing the symptom at the tendon.

To my surprise research had found that no actual inflammation was ever identified in tendons that had demonstrated clinical evidence of tendonitis. ${ }^{24} \mathrm{I}$ then found research demonstrating the microcirculation of the 
tendon itself and research supporting the potential ischemia of the tendon itself with the chronic pull of a muscle in chronic spasm. ${ }^{25}$

I postulated that tendonitis was an ischemic event of the tendon which explained the time necessary for recovery after the attached muscle was no longer in spasm.

\section{Hierarchy of Pain}

A final abstract submitted in 2019 was not accepted. I believe it likely should have been submitted els ewhere. It was entitled: $\mathrm{CMECD}^{\circledR}$ Experience Regarding Apparent Failed Pain Treatments.

The full text is available on the CMECD.info website but the finding can be most simply characterized by the concept of: "Hierarchy of Pain", which phrase parenthetically was coined by my wife. This phenomenon is therefore presented here for the first time because it interferes with the assessment of the success of the pain intervention.

What became apparent over time was that with the immediate and successful treatment of one site of chronic pain there was frequently the nearly immediate complaint of another site of pain. In one case it actually happened that after successfultreatment of the right arm the patient then complained immediately of pain in his left arm. This phenomenon, which was reproducible, confounds the assessment of success especially for sites of spasm and pain of in close proximity.

It appears that the brain will focus on the apparent most significant threat to life but will quickly alter course to the next most significant threat with resolution of the first. This led to a careful reappraisal of the injection technique with marking sites of perceived pain on the skin.

After injection of that site, assuming that it resulted in relief of the pain at that site, the patient would be questioned regarding residual pain. Often an adjacent site would then be identified as painful. That site would be marked and then interrogated for the appearance of SEA. If found, the second site would then be treated. There was a fixed amount of medication that had been found that could be safely administered, which was $20 \mathrm{ml}$ of the final solution.

Routinely, after half of the solution was used, the patient was asked to get up off the stretcher or the injection chair to check for lightheadedness and to better assess for additional or residual sites of pain. This was important also because many sites of pain only occurred on a given stance, motion or use of a limb.

Attempts to reproduce the initial pain or identify a second site of pain improved the overall success of the intervention as residual or new sites could then be targeted. This resultant understanding of perception of pain was key to performing more successful interventions.

Thus, any attempt to design a future study for relief of chronic pain needs to take into account this phenomenon of "Hierarchy of Pain".

\section{Hibernating Skeletal Muscle}

What I started out to do was find the cause of chronic muscle spasmand find a way to give relief for individuals in chronic pain. SEA was found to be both the signature and cause of chronic spasm. The $\mathrm{CMECD}^{\circledR}$ procedure while invasive does provide an effective treatment. Arriving at that point of understanding required a paradigm shift not only in perspective but also in methods of treatment.

The ischemic model of chronic muscle spasm was supported by the findings of Ugo Carraro, ${ }^{9,10}$ with what I can now call "hibernating skeletal muscle".

New conceptualmodels of this sort in medicine typically take 20 years to be both conceptually and practically accepted. I have authored a book, potentially already in print by the time this essay is printed, entitled "Chronic Muscle Spasm and Pain - Discoveries in the Etiology, Identification and Treatment of Chronic Muscle Spasm and Resultant Chronic Pain".

While the book is a bit casual for a scientific audience, I believe it makes a case for re-evaluating our current understanding and treatment of chronic muscle spasm and chronic pain.

\section{Conclusions}

What began 15 years ago in a search for the cause of chronic muscle spasm has led to finding the proximal cause of chronic muscle spasm, a technique for its identification and a successfultreatment protocol.

In the process, the underlying mechanism that led to the occurrence of chronic muscle spasm, became apparent. The Ischemic Model of Chronic Muscle Spasm was able to tie together the loose ends of the EMG and clinical findings.

As a single individual attempting to succeed in this endeavor, trials and errors were required. I used myself as a subject before treating any patient. My experience as an early provider of coronary intervention and being active in its development, gave me guidance to keep within professional guidelines.

The trust of my patients allowed me to develop this procedure, as there was little opportunity or support for a full-fledged clinical trial. What will hopefully result by this publication is exactly that, a full-fledged clinical trial. There also should be the opportunity for basic research to prove or disprove the is chemic model.

Finally, it was shown that chronic pain could be relieved without the use of opioid medications or surgical procedures. With eventual acceptance of this and other procedures derived from the ischemic model, a lessening of the current opioid crisis may be possible.

\section{List of acronyms}

Botox $^{\circledR}$ - Onabotulinumtoxin A

$\mathrm{CMECD}^{\circledR}$ - Coletti Method of EMG ChemoDenervation

CMECD.info - The website for CMECD ${ }^{\circledR}$

EMG - Electromyography

SEA - Spontaneous Electrical Activity 


\section{Contributions of Author}

The author drafted, wrote, revised and provided final approval of the edited typescript.

\section{Acknowledgments}

The authors would like to thank Ugo Carraro for his encouragement and support.

\section{Funding}

This research received no external funding.

\section{Conflict of Interest}

The author declares no competing interests.

\section{Ethical Publication Statement}

I confirm that I have read the Journal's position on ethical publication issues and affirms that this report is consistent with those guidelines.

\section{Corresponding Author}

Roger H. Coletti, Interventional Health. PA. USA, Address: Suite 125, 16529 Coastal Highway, Lewes, DE 19958-3697

Phone: +01-302-645-1500.

ORCID ID: 0000-0003-2569-4435

Email: rogercoletti@gmail.com

\section{References}

1. Dirksen RT. Sarcoplasmic reticulum-mitochondrial through-space coupling in skeletal muscle. Appl Physiol Nutr Metab. 2009 Jun;34(3):389-95. doi: 10.1139/H09-044.

2. Minerbi A, Vulfsons S. Challenging the Cinderella Hypothesis: A New Model for the Role of the Motor Unit Recruitment Pattern in the Pathogenesis of Myofascial Pain Syndrome in Postural Muscles. Rambam Maimonides Med J. 2018 Jul 30;9(3):e0021. doi: 10.5041/RMMJ.10336.

3. Mazza DF, Boutin RD, Chaudhari AJ. Assessment of Myofascial Trigger Points via Imaging: A Systematic Review. Am J Phys Med Rehabil. 2021 Oct 1;100(10):1003-1014. doi: 10.1097/PHM. 0000000000001789.

4 Gerwin RD, Dommerholt J, Shah JP. An expansion of Simons' integrated hypothesis of trigger point formation. Curr Pain Headache Rep. 2004 Dec;8(6):468-75. doi: 10.1007/s11916-004-0069-x.

5. Ghuran AV, Camm AJ. Ischaemic heart disease presenting as arrhythmias. $\mathrm{Br}$ Med Bull. 2001;59:193-210. doi: 10.1093/bmb/59.1.193.

6. Zile MR, Baicu CF, Gaasch WH. Diastolic heart failure--abnormalities in active relaxation and passive stiffness of the left ventricle. N Engl J Med. 2004 May 6;350(19):1953-9. doi: 10.1056/NEJMoa032566.

7. Umana E, Solares CA, Alpert MA. Tachycardiainduced cardiomyopathy. Am J Med. 2003 Jan;114(1):51-5. doi: 10.1016/s00029343(02)01472-9
8. Kloner RA. Stunned and Hibernating Myocardium: Where Are We Nearly 4 Decades Later? J Am Heart Assoc. 2020 Feb 4;9(3):e015502. doi: 10.1161/JAHA.119.015502. Epub 2020 Feb 4.

9. Ravara B, Gobbo V, Carraro U, Gelbmann L, Pribyl J, Schils S. Functional Electrical Stimulation as a Safe and Effective Treatment for Equine Epaxial Muscle Spasms: Clinical Evaluations and Histochemical Morphometry of Mitochondria in Muscle Biopsies. Eur J Transl Myol. 2015 Mar 11;25(2):4910. doi: 10.4081/ejtm. 2015.4910.

10. Schils S, Carraro U, Turner T, Ravara B, Gobbo V, Kern H, Gelbmann L, Pribyl J. Functional Electrical Stimulation for Equine Muscle Hypertonicity: Histological Density and Distribution, Journal of Equine Veterinary Science 2015; 35: 907-916.

11. Simons DG. Cardiology and myofascial trigger points: Janet G. Travell's contribution. Tex Heart Inst J. 2003;30(1):3-7.

12. Hubbard DR. Myofascial trigger points show spontaneous needle EMG activity. Hubbard DR, Berkoff GM. Spine (Phila Pa 1976). 1993 Oct 1;18(13):1803-7. doi: 10.1097/00007632199310000-00015. PMID: 8235865].

13. Hubbard DR. Chronic and Recurrent Muscle Pain: Pathophysiology and Treatment, and Review of Pharmacologic Studies in Clinical Overview and Pathogenesis of the Fibromyalgia Syndrome, and Other Pain Syndromes. Jon Russel, M, Editor, The Hawthorne Medical Press, 1996. Pages 123-142.

14. Press Release - University of Calgary. Botulinum toxin A creates muscle weakness and atrophy following long term use, study suggests. ScienceDaily. ScienceDaily, 2 December 2010. www.sciencedaily.com/releases/2010/12/1012021 24248.htm.

15. V1: Treatment of IT Band Syndrome with injection of the tensor fascia lata muscle: https ://www.youtube.com/watch?v=f6npZiwNs 7s .

16. V2: Cessation of SEA with the injection: https://www.youtube.com/watch?v=bQrhNlOjOvw.

17. V3: Treatment of chronic back muscle spasm with CMECD $^{\circledR}$ procedure: https://www.youtube.com/ watch?v=fAAfK5n3uP8.

18. Mills KR. The basics of electromyography. J Neurol Neurosurg Psychiatry. 2005 Jun;76 Suppl 2(Suppl 2):ii32-5. doi: 10.1136/jnnp.2005.069211.

19. Coletti R, Proposd new diagnostic entity of acquired chronic muscle spasm. Abstract in Muscle \& Nerve, Volume 58/ No. S2/September 2018, Pages: S1-S120; First Published: 02 October 2018, page S34, https://onlinelibrary.wiley.com/toc/1097 4598/58/S2.

20. Coletti R. EMG guided chemodenervation procedure of acquired chronic muscle spasm designated as $\mathrm{CMECD}^{\circledR}$. Abstract in Muscle \& Nerve, Volume 58/ No. S2/September 2018, Pages: S1-S120; First Published: 02 October 2018, Page 


\section{Chronic pain secondary to muscle spasm}

Eur J Transl Myol 32 (1): 10323, 2022 doi: 10.4081/ejtm.2022.10323

S36, https://onlinelibrary.wiley.com/toc/10974598/ $\underline{58 / S 2}$.

21. Coletti R. Limitations of EMG and nerve conductionstudies in clinical practice. Abstract in Muscle \& Nerve, Volume 58/ No. S2/September 2018, Pages: S1-S120; First Published: 02 October 2018, page S31, Page S36, https://online library.wiley.com/toc/10974598/58/S2.

22. Coleti R. Non skeletal ethiology of foot drop with therapeutic reversal. Abstracts 2019 AANEM Annual Meeting Abstract Guide Austin, TX, October 16-19, 2019 Muscle \& Nerve, Volume 60, Issue S1 First published: 13 August 2019, https://doi.org/10.1002/mus.26647 .

23. Vadivelu N, Kai AM, Kodumudi V, Sramcik J, Kaye AD. The Opioid Crisis: a Comprehensive
Overview. Curr Pain Headache Rep. 2018 Feb 23;22(3):16. doi: 10.1007/s11916-018-0670-z.

24 Movin T, Gad A, Reinholt FP, Rolf C. Tendon pathology in long-standing achillodynia. Biopsy findings in 40 patients. Acta Orthop Scand. 1997 Apr;68(2):170-5. doi: 10.3109/1745367970900 4002.

25. Chen TM, Rozen WM, Pan WR, Ashton MW, Richardson MD, Taylor GI. The arterial anatomy of the Achilles tendon: anatomical study and clinical implications. Clin Anat. 2009 Apr;22(3):377-85. doi: 10.1002/ca.20758.

Submitted: December 17, 2021 Revision received: January 7, 2021 Accepted for publication: January 8, 2022 